\title{
Low cycle fatigue behavior of additively manufactured Ti-6Al-4V under non-proportional and proportional loading
}

\author{
Stefano Bressan \\ Ritsumeikan University, Graduate School of Science and Engineering, 1-1-1, Nojibigashi, Kusatsu-shi, Shiga, 5258577, Japan \\ gr0300kf@ed.ritsumei.ac.jp
}

Fumio Ogawa, Takamoto Itoh

Ritsumeikan University, Department of Mechanical Engineering, 1-1-1, Nojibigashi, Kusatsu-shi, Shiga, 5258577, Japan itobtaka@ff.ritsumei.ac.jp

ogawa-f@fcritsumei.ac.jp

\section{Filippo Berto}

Norwegian University of Science and Technology, Department of Engineering Design and Materials, Richard Birkelands vei 2b, 7491, Trondheim, Norway

filippo.berto@ntnu.no

ABSTRACT. Experimental tests were conducted on additive manufactured Ti$6 \mathrm{Al}-4 \mathrm{~V}$ titanium alloy to investigate the mechanical and crack properties under multiaxial cyclic loading. Selective Laser Sintering technique (SLS) was employed to fabricate four types of cylindrical hollow specimens. The typology of each specimen is defined by the orientation of the layers and by the application of a stress-relieving heat treatment after the production process. Stress-strain cyclic curves of the materials were obtained to investigate the material cyclic plastic behavior, that resulted independent of specimen variety. Strain-controlled multiaxial low cycle fatigue tests under proportional and non-proportional loading paths were carried out on the specimens. Not heat-treated specimens exhibited a higher low cycle fatigue resistance both for proportional and non-proportional loading. Drastic initial softening was detected in the majority of the tests. Additional hardening was detected in part of non-proportional tests, which is atypical for this alloy. The mutual influence of applied load and microstructural characteristics on fatigue life are finally discussed.

KEYwORDS. Additive manufacture; Titanium; Low cycle fatigue; Multiaxial non-proportional loading.

\section{OPEN $\bigcirc$ ACCESS}

Citation: Bressan, S., Ogawa, F., Itoh, T., Berto, F. Low cycle fatigue behavior of additively manufactured Ti-6Al-4V under non-proportional and proportional loading, Frattura ed Integrità Strutturale, 48 (2019) 1825

Received: 27.11 .2018

Accepted: 13.12 .2018

Published: 01.04.2019

Copyright: (C) 2019 This is an open access article under the terms of the CC-BY 4.0, which permits unrestricted use, distribution, and reproduction in any medium, provided the original author and source are credited. 


\section{INTRODUCTION}

$\mathrm{I}$ $\mathrm{n}$ the recent years, additive manufacturing (AM) or $3 \mathrm{D}$ printing fabrication technique has been increasingly applied for the production of a wide variety of mechanical components. The term additional manufacturing indicates the fabrication of components through a subsequent deposition of layers created through the fusion of metal powders $[1,2]$. Among the metals that can be fabricated with AM techniques, Ti- $6 \mathrm{Al}-4 \mathrm{~V}$ occupies a central position. Aero engines turbine blades and medical prosthesis are the most representative examples of AM components made of this alloy. Several additive manufacturing processes have been developed, each with advantages and disadvantages [3-5]. Powder bed system is the most employed AM process and consists of using a laser or an electron beam to selectively melt the surface of a powder-bed to create a cross sectional layer of the component. The process repeats itself until the creation of the final component. Powder feed systems directly deposit powder on a surface allowing to create larger components or even repair damaged parts. Finally, wire feed systems employ a wire of the desired material to build the component through deposition of subsequent layers. High deposition rate and large volumes characterize this process which however cannot be employed for complex geometries and requires more extensive machining after process than the other techniques. Despite of the advantages of AM techniques, some weaknesses are also present: rough surface of the components, presence of defects generated by trapped gas or lack of fusion, and residual stresses due to the repeated fusionsolidification phenomena involved during the fabrication. Mechanical or thermal post fabrication processes are therefore necessary to optimize the material properties and fatigue performances. The multitude of process typologies and process parameters that can be selected (laser thickness, laser speed, etc.) represents an issue for a correct and unambiguous definition of the mechanical and fatigue properties of additively manufactured materials. In fact, several works on AM Ti$6 \mathrm{Al}-4 \mathrm{~V}$ evidenced that material structure and so mechanical properties are closely related to process parameters [6-9]. Martensitic (acicular) structure characterizes materials made with AM processes due to the rapid cooling rate in the fabrication chamber. The static properties such as ultimate tensile strength, yield stress and elongation to failure have been found comparable to those of the wrought titanium. The observed differences in such properties were due to the anisotropy caused by the layer orientation of the tested specimens. Uniaxial fatigue properties have been also widely investigated and the number of cycles to failure resulted dependent on the additive manufacturing technique and the post process treatments [10-15]. The fatigue properties are comparable with the traditionally manufactured titanium depending on the case. The determinant factors on fatigue strength are surface finish and presence of voids. Specimens with a rough surface exhibited a shorter fatigue life for the majority of the cases. Cracks initiating from superficial voids leading to fatigue failure have been also observed. [10].

Non-proportional loading occurs when the direction of the principal stress during the cycle changes and provokes a reduction of failure life [16]. Although several works have been conducted on non-proportional loads applied to traditionally manufactured materials, the investigations of fatigue behavior of AM metals under multiaxial nonproportional loading are still sparse. Some remarkable work conducted by Fatemi et al. discussed the results of nonproportional multiaxial stress-controlled tests conducted on heat-treated AM titanium with the same layer orientation [17]. The crack was found initiating from both surface and internal defects and the failure life could be evaluated with critical plane models.

In this research, the mutual influence of layer orientation, stress-relieving heat treatment and voids on uniaxial and multiaxial low cycle fatigue was analyzed. Four types of specimens characterized by a different orientation of the layers and by the presence or absence of a post process stress-relieving heat treatment have been analyzed. The material microstructure has been observed to investigate the influence of heat treatment and layer on the structure. The cyclic curves of the materials have been obtained for each specimen to analyze the plastic cyclic behavior. Proportional and nonproportional strain paths have been applied to verify the dependence of both failure life and fracture mechanism on the specimen variety. Softening and hardening curves and cracks have been finally discussed to verify the failure life dependence and fracture mechanism depending on the specimen variety.

\section{SPECIMENS}

7 he specimens have been fabricated with the SLS (selective laser sintering) technique employing Ti-6Al-4V powders. The types of specimens are four, depending on the layer orientation and the post process heat treatment performed. The orientation of the specimen is defined horizontal $(\mathrm{H})$ if the plane defined by the layer is parallel to the specimen axis or vertical (V) if the plane defined by the layer is perpendicular to the specimen axis (Fig. 1). The post process stress-relieving heat treatment has been performed on part of the samples at $800^{\circ} \mathrm{C}$ for 4 hours in argon 
atmosphere after the fabrication process. The nomenclature of the specimens indicates the fabrication direction $(\mathrm{H}, \mathrm{V})$ and the presence $(\mathrm{T})$ or absence $(\mathrm{NT})$ of the post process heat treatment. The four varieties of specimens are therefore HT, HNT, VT, VNT. After the 3D printing process, the specimens have been machined to obtain the final geometry for the experimental tests (Figs. 2a and b). The static mechanical properties (ultimate tensile stress (UTS), yield strength $\left(\mathrm{Y}_{0,2}\right)$ and elongation to break $(\mathrm{A})$ ) and their dependence from the layer direction and heat treatment are listed in Tab. 1.

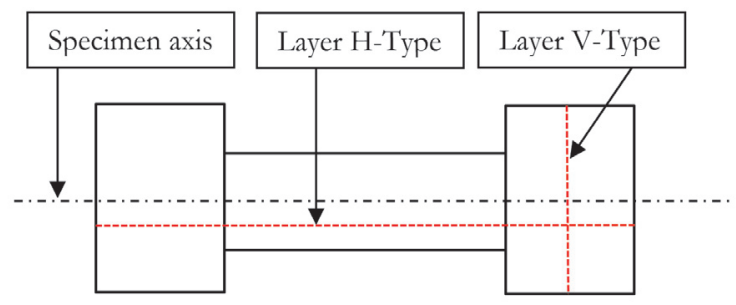

Figure 1: Layer orientation.

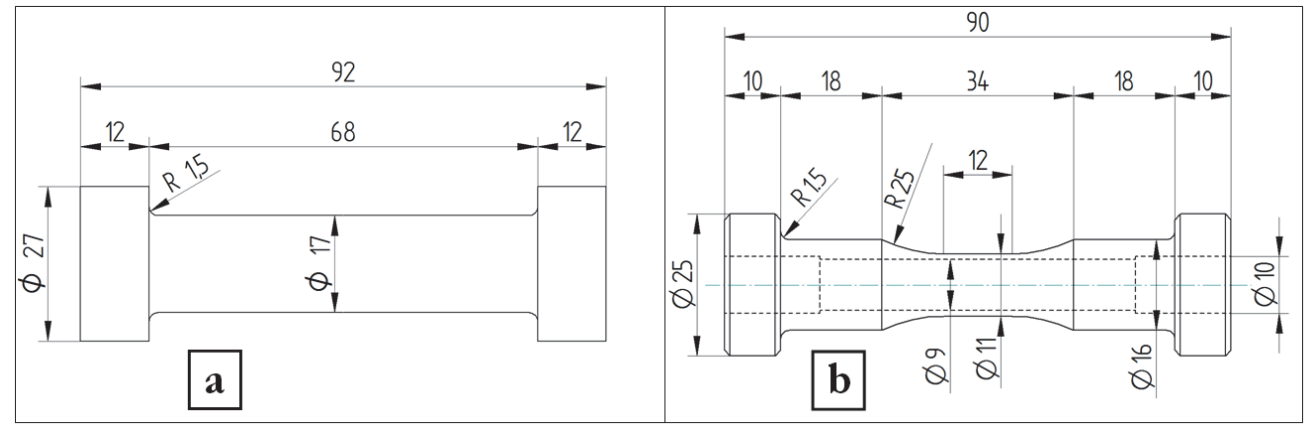

Figure 2: Specimen before machining (a) and specimen after machining (b) (mm).

\begin{tabular}{cccc}
\hline Specimen type & UTS & $\mathrm{Y}_{0,2}$ & $\mathrm{~A}$ \\
HT & $\mathrm{MPa}$ & $\mathrm{MPa}$ & $\%$ \\
HNT & 1050 & 860 & 10 \\
VT & 1230 & 1060 & 14 \\
VNT & 1060 & 860 & 11 \\
\hline
\end{tabular}

Table 1: Typical static mechanical properties for each specimen type.

\section{MiCROSTRUCTURE}

1

he material microstructure has been analyzed to investigate the microstructural differences depending on the specimen variety. The surface has been subject to chemical attack with an etching solution of $\mathrm{HF}, \mathrm{HNO}_{2}$ and distilled water. The observed specimen surface is depicted in Fig. 3.

Each specimen presents a martensitic acicular microstructure (Figs. $4 \mathrm{a}$ and b). The heat treatment performed to release the residual stresses is not such as to induce phase transformation, grain coarsening, etc. The elongated prior $\beta$-grains are visible in the form of dark and light areas, which depend on the crystal orientation. The direction of the prior $\beta$-grains depends on the layer orientation and the average length of the grain was measured $200 \mu \mathrm{m}$. The axis of the elongated prior $\beta$-grains is perpendicular to the layer. The heat flow direction is perpendicular to the layer and by consequence the grain growth direction results to be perpendicular to the layer [18]. Voids with the average size of $30 \mu \mathrm{m}$ have been detected in each specimen. The voids were spherical, isolated and mostly on the inner surface. The void density and dimension were independent of heat treatment and layer orientation. 


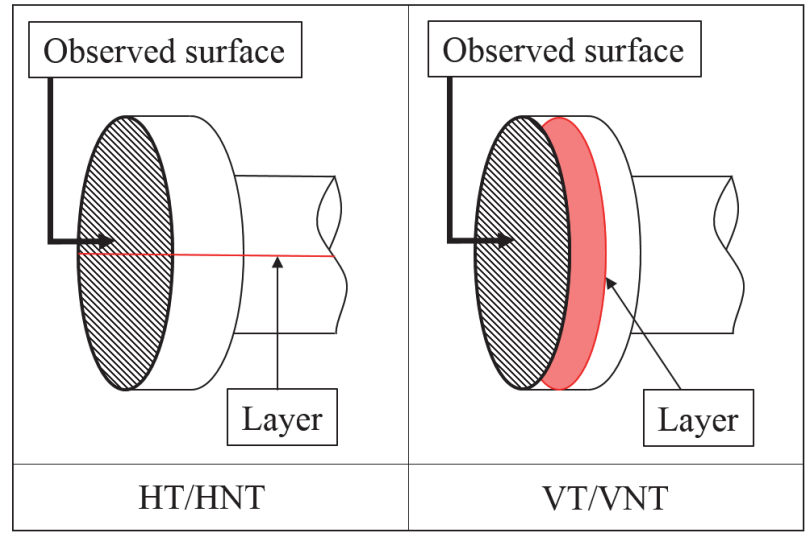

Figure 3: Observation surface

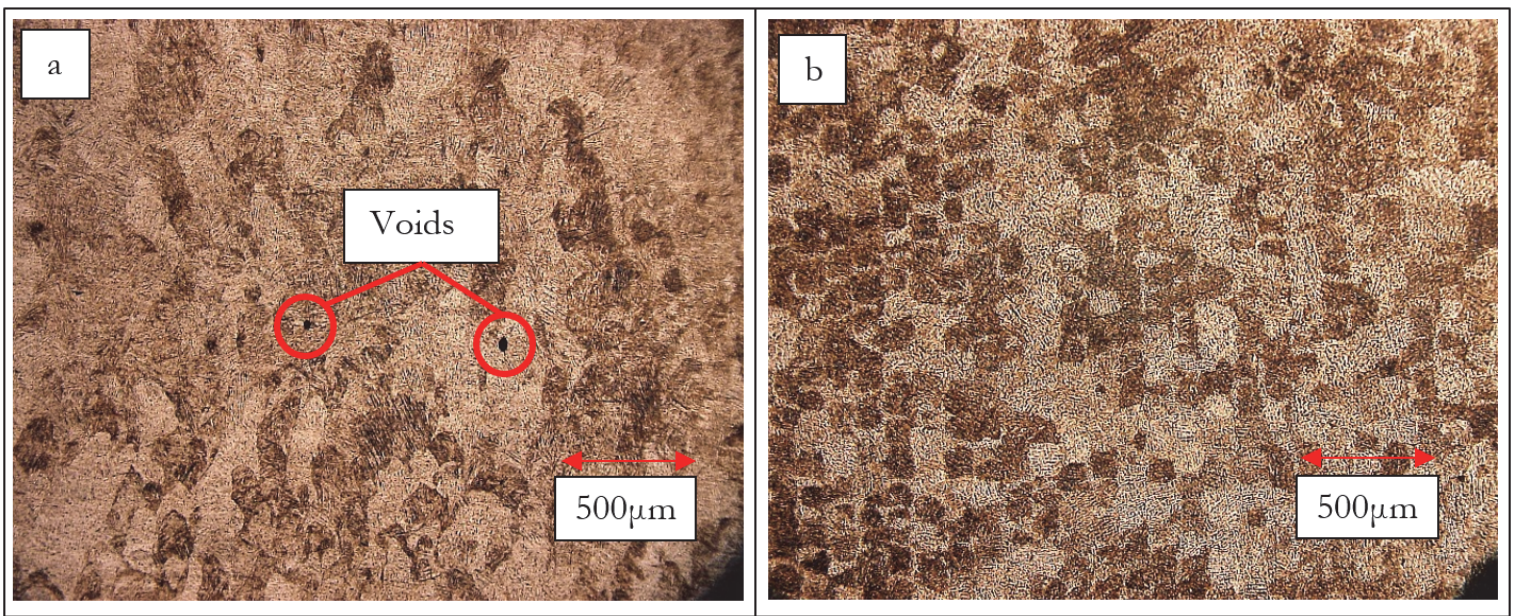

Figure 4: Microstructure of horizontal (a) and vertical (b) specimens

\section{STRESS-STRAIN CYCLIC CURVES}

7 he stress-strain cyclic curves of the material have been obtained by performing a step-up test for both proportional and non-proportional strain paths. The proportional strain is represented by a push-pull (PP) test, while the non-proportional loading is represented by a circle loading path (CI) (Fig. 5).

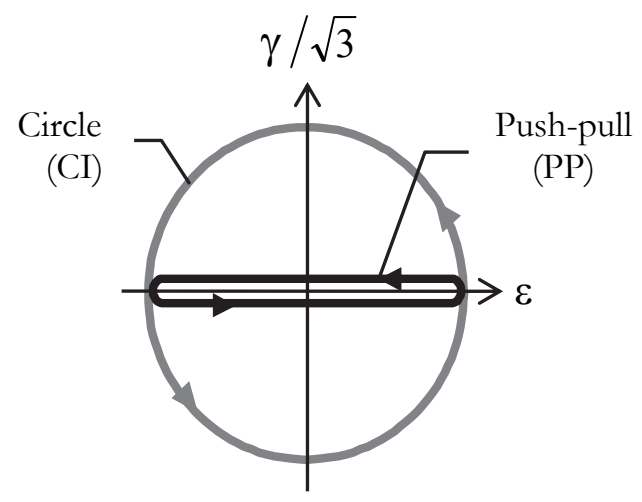

Figure 5: Applied strain paths. 
The stress-strain cyclic curves of the material have been obtained through an incremental step test. The incremental step test consists in increasing the equivalent strain range $\Delta \varepsilon_{\text {eq }}$ by $0.1 \%$ every 10 cycles. Each type of specimen has been tested with both proportional and non-proportional strain path, and the results are represented in Figs. 6a and b.

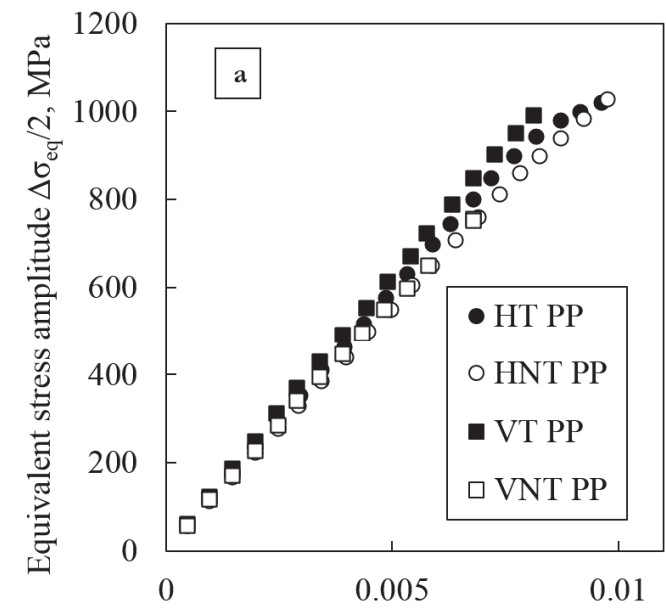

Equivalent strain amplitude $\Delta \varepsilon_{\mathrm{eq}} / 2, \%$

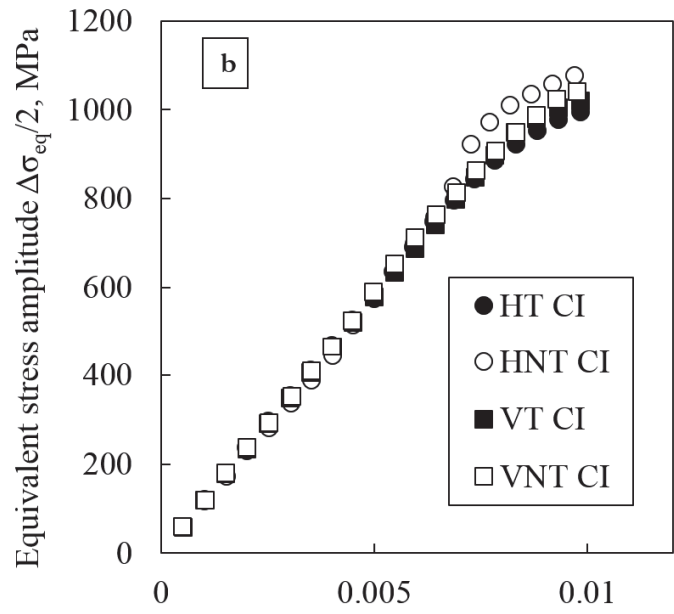

Equivalent strain amplitude $\Delta \varepsilon_{\mathrm{eq}} / 2, \%$

Figure 6: PP strain path cyclic curves (a) and CI strain path cyclic curves (b) for each specimen type.

Layer orientation and heat treatment appear not to have influence on the cyclic behavior of the material. In case of pushpull the not heat-treated material has lower stress response for the same applied strain. Compared to proportional loading, non-proportional loading is characterized by an earlier transition between elastic and plastic behavior. Curves for CI are more similar than curves for PP. No additional hardening has been detected in non-proportional cyclic curves analogous to with the wrought titanium [19].

\section{FATIGUE TESTS}

\section{Experimental procedure}

7 he specimens have been tested with a servo-hydraulic machine which can apply simultaneously push-pull and reverse torsion strain paths. The strain for the strain-controlled tests are measured by means of an extensometer connected to the specimen. Push-pull and circle strain paths have been applied to each specimen with an equivalent strain range $\Delta \varepsilon_{\mathrm{eq}}=1.8 \%$ in order to provoke plastic deformation. The number of cycles to failure $N_{\mathrm{f}}$ is defined as the number of cycles where the stress amplitude becomes $3 / 4$ of the maximum stress amplitude recorded in the test.

\section{Fatigue tests results}

The number of cycles of failure for each specimen and cycle is listed in Tab. 2.

\begin{tabular}{ccc}
\hline Specimen type & $N_{\mathrm{f}} \mathrm{PP}$ & $N_{\mathrm{f}} \mathrm{CI}$ \\
HT & 1426 & 300 \\
HNT & 1623 & 412 \\
VT & 1268 & 374 \\
VNT & 1795 & 464 \\
\hline
\end{tabular}

Table 2: Number of cycles to failure for PP and CI. 
The number of cycles to failure in the case of CI strain paths is approximately the $25 \%$ of the number of cycles to failure in the case of PP. The not heat-treated specimens exhibited a longer fatigue life than the heat-treated specimens. The layer orientation seems having a minor influence on failure life compared to the heat-treatment case, similar to the trends of the static mechanical properties. VNT specimen has the longest life for both PP and CI, followed by HNT. The $N_{\mathrm{f}}$ of HT is the lowest for CI, and $N_{\mathrm{f}}$ of VT is the lowest for PP.

\section{Hardening and softening curves}

The hardening and softening curves have been investigated (Figs. $7 \mathrm{a}$ and b). For the sake of brevity, only the curves of horizontal specimens are reported.
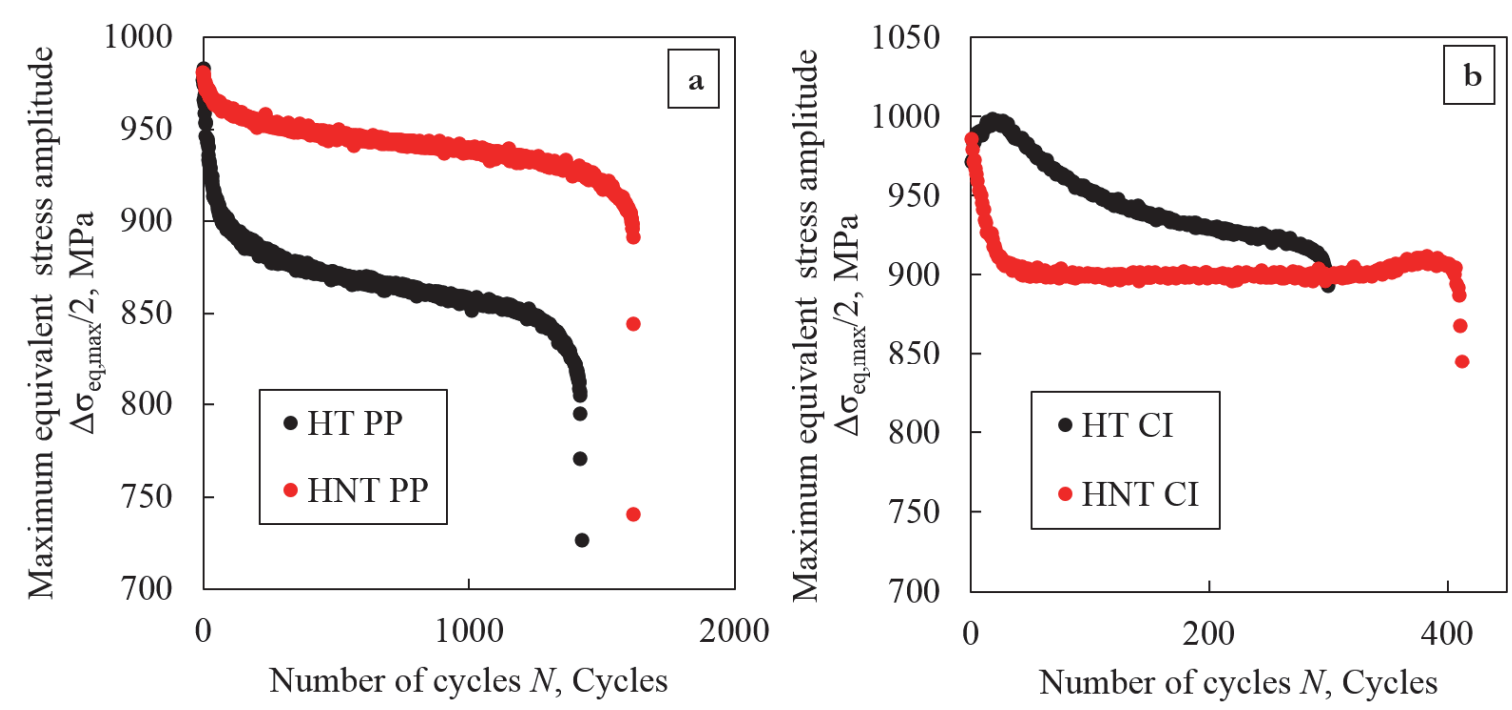

Figure 7: Hardening and softening curves for HT and HNT type specimens for PP (a) and CI (b) strain paths.

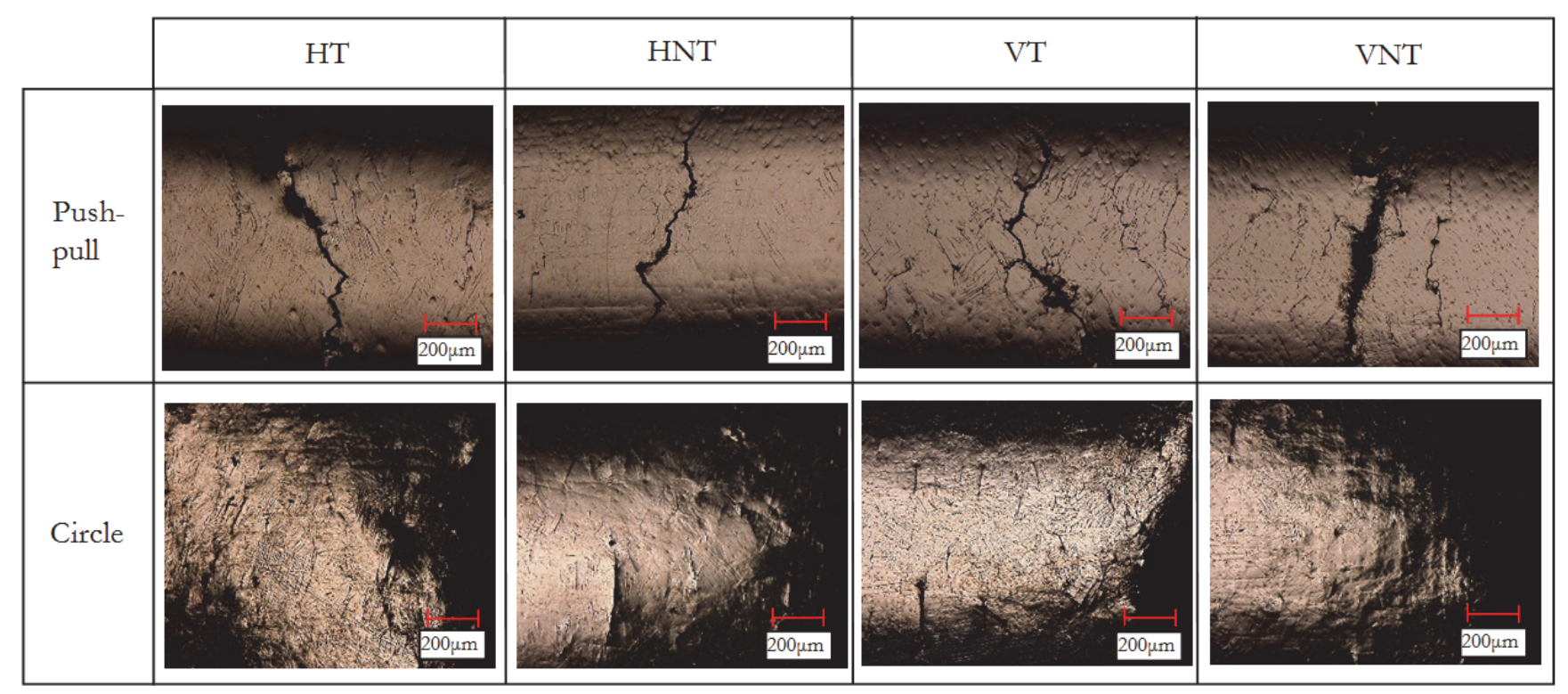

Figure 8: Surface of the specimens after fracture.

From such hardening/softening curves, significant information about the material behavior can be deducted. The heat treatment influences the stress value for both PP and CI. In case of PP, the heat-treated component experiences a higher softening decrease (Fig. 7 a). In CI, the softening behavior occurs for the not heat-treated specimen. The initial softening 
behavior observed for the majority of the tests is thought to be caused by an early crack initiation on internal voids. Such cracks provoke a decrease of the stress until the magnitude of stress is sufficient for the crack to further propagate. After the first softening phase, the softening process continues up to the final crack propagation in the majority of the test. In case of HNTCI, after the initial softening, the softening and hardening behavior is stabilized up to the final fracture propagation (Fig. 7 b). A weak hardening phenomenon has been observed in HTCI. Additional hardening has not been detected for wrought titanium, and represents an anomalous behavior for this material. The cause is not clear.

\section{Crack observation}

Cracks were observed on the specimen surface through an optical microscope. The surface cracks are represented in Fig. 8. In the case of CI, the fracture completely propagated, leading to the rupture of the specimen. In Fig. 8 it can be observed that the heat-treated specimens present a higher microcrack density on the surface. The crack orientation depends on the applied load, and a direct connection with the layer orientation could not be observed. Cracks initiating from superficial voids could be also observed in several cases, although the crack did not lead to failure. In some cases, the main crack path intersects superficial voids. However, given that the crack initiation process was not investigated, it is impossible to determine whether the crack initiated from such external defects.

\section{DISCUSSION}

7 he influences on fatigue behavior of heat treatment, layer orientation and voids are discussed hereafter. The layer orientation determines the grain orientation of the prior $\beta$ grains due to the different growth direction of the grains. Voids shape, voids number and material microstructure are not influenced by the layer orientation. The number of cycles to failure does not have a close relationship with layer orientation. However, the layer orientation affects the softening and hardening behavior as well as the stress levels (Fig. 7).

The heat treatment was found to be the most influent factor on the number of cycles to failure for the applied strain range. Residual stresses provoked by the repeated fusion-solidification processes and high cooling rate have a beneficial effect in terms of failure life (Tab. 2). The hardening/softening curves reveal that the heat-treated components tested with non-proportional loading exhibit an additional hardening behavior at the beginning of the tests. This behavior has not been observed in the plastic cyclic curves, and the cause could not be detected. The additional hardening might also play a role in the earlier failure of HTCI and VTCI compared to HNTCI and VNTCI. The incremental step method employed to extrapolate the cyclic stress might also be not suitable to detect such a phenomenon as the time for the hysteresis loop to stabilize is not sufficient being only 10 cycles for each applied strain range.

Fatigue life results show that heat treatment has a higher influence than voids. However, cracks initiating from internal voids might be the cause of the sudden softening effect observed in the majority of the specimens. In fact, since the tests have been conducted under strain-controlled conditions, the stress rapidly decreases due to the early crack formation. Future research will be focused on observing the crack initiation and the correlation between softening and internal crack initiation on voids.

\section{CONCLUSIONS}

$\mathrm{P}$ roportional and non-proportional low cycle fatigue tests have been conducted on four types of additively manufactured Ti-6Al-4V specimens. The specimen type is defined by the layer orientation post process stressrelieving heat treatment. The material microstructure has been observed and discussed. Cyclic curves have been obtained by means of a step-up test. Fatigue tests with a push-pull (PP) and circle strain paths (CI) have been conducted, and the number of cycles to failure, softening and hardening curves and cracks have been analyzed to investigate the influence of layer orientation, voids and heat treatment on the low cycle fatigue behavior. The conclusions can be summarized as follows:

- Heat treatment on additively manufactured Ti-6Al-4V has a detrimental effect on low cycle fatigue life, for both nonproportional and proportional loading.

- Early sudden softening was observed for tests conducted with high strain range, and it is thought to be correlated with the formation of cracks in internal voids.

- Non-proportional loading provokes an anomalous additional hardening effect on heat-treated specimens and could represent the cause of the earlier failure compared to not heat-treated specimens. 
- Layer orientation influences the prior $\beta$ grain orientation and the stress levels during the tests. Failure life for both proportional and non-proportional loading is not affected by the layer orientation.

\section{REFERENCES}

[1] Kruth, J.P., Leu, M.C., Nakagawa, T. (1998). Progress in Additive Manufacturing and Rapid Prototyping, CIRP Ann., 47, pp. 525-540. DOI: 10.1016/S0007-8506(07)63240-5.

[2] Levy, G.N., Schindel, R., Kruth, J.P. (2003). Rapid Manufacturing and Rapid Tooling whit Layer Manufacturing (LM) Technologies, State of the Art and Future Perspectives, CIRP Ann. 52, pp. 589-609.

DOI: 10.1016/S0007-8506(07)60206-6.

[3] Frazier, E.W. (2014). Metal additive manufacturing: a review, ASM Int., 23, pp. 1917-1928. DOI: $10.1007 /$ s11665-014-0958-z.

[4] Shiomi, M., Osakada, K., Nakamura, K., Yamashita, T., Abe, F. (2004). Residual Stress within Metallic Model Made by Selective Laser Melting Process, CIRP Ann. 53, pp. 195-198. DOI: 10.1016/S0007-8506(07)60677-5.

[5] Leuders, S., Thöne, M., Riemer, A., Niendorf, T., Tröster, T., Richard, H.A. et al. (2013). On the Mechanical Behaviour of Titanium Alloy TiAl6V4 Manufactured by Selective Laser Melting: Fatigue Resistance and Crack Growth Performance, Int. J. Fatigue. 48, pp. 300-307. DOI: 10.1016/j.ijfatigue.2012.11.011.

[6] Kobryn, P.A. and Semiatin, S.L. (2001). Microstructure and Mechanical Properties of Ti-6Al-4V Parts Fabricated by Laser Engineered Net Shaping, in: Solid Free. Fabr. Proc., Austin, pp. 6-8.

[7] Edwards, P. amd Ramulu, M. (2014). Fatigue performance evaluation of selective laser melted Ti-6Al-4V, Mater. Sci. Eng., 598, pp. 327-337. DOI: 10.1016/j.msea.2014.01.041.

[8] Xu, W., Sun, S., Elambasseriil, J., Liu, Q., Brandt, M., Qian, M. (2015). Ti-6Al-4V additively manufactured by selective laser melting with superior mechanical properties, J.O.M., 67(3), pp. 668-673. DOI: 10.1007/s11837-015-1297-8.

[9] Edwards, P., O'Conner, A., Ramulu, M. (2013). Electron beam additive manufacturing of titanium components: properties and performances. J. Manuf. Sci. Eng., 135(6), 061016. DOI: 10.1115/1.4025773.

[10] Li, P., Warner, D.H., Fatemi, A., Phan, N. (2016). Critical assessment of the fatigue performance of additively manufactured Ti-6Al-4V and perspective for future research, Int. J. Fatigue, 85, pp. 130-143. DOI: $10.1016 /$ j.ijfatigue.2015.12.003.

[11] Rafi, H.K., Starr, T.L., Stucker, B.E. (2013). A Comparison of the Tensile, Fatigue, and Fracture Behavior of Ti-6Al4V and 15-5 PH Stainless Steel Parts Made by Selective Laser Melting, Int. J. Adv. Manuf. Technol., 69, pp. 12991309. DOI: $10.1007 / \mathrm{s} 00170-013-5106-7$.

[12] Rekedal, K., and Liu, D. (2015). Fatigue Life of Selective Laser Melted and Hot Isostatically Pressed Ti-6Al-4V Absent of Surface Machining, in: Proc. 56th AIAA/ASCE/AHS/ASC Struct. Struct. Dyn. Mater. Conf., Kissimmee, FL.

[13] Seifi, M., Dahar, M., Aman, R., Harrysson, O., Beuth, J., Lewandowski, J.J. (2015). Evaluation of Orientation Dependence of Fracture Toughness and Fatigue Crack Propagation Behavior of As-Deposited ARCAM EBM Ti-6Al4V, JOM. 67, pp. 597-607. DOI: 10.1007/s11837-015-1298-7.

[14] Wycisk, E., Solbach, A., Siddique, S., Herzog, D., Walther, F., Emmelmann, C. (2014). Effects of Defects in Laser Additive Manufactured Ti-6Al-4V on Fatigue Properties, Phys. Procedia. 56, pp. 371-378.

DOI: $10.1016 /$ j.phpro.2014.08.120.

[15] Rekedal, K.D. and Liu, D. (2015). Fatigue life of selective laser melted and hot isostatically pressed Ti-6Al-4V absent of surface machining. In: Proceedings of the 56 th AIAA/ASCE/AHS/ASC structures, structural dynamics, and material conference, Kissimee, FL.

[16] Kanazawa, K., Miller, K.J., Brown, M.W. (1979). Cyclic Deformation of 1\% Cr-Mo-V Steel Under Out-of-Phase Loads, Fatigue Fract. Eng. Mater. Struct. 2, pp. 217-228. DOI: 10.1111/j.1460-2695.1979.tb01357.x.

[17] Fatemi, A., Molaei, R., Sharifimehr, S., Phan, N., Shamsaei, N. (2017). Multiaxial fatigue behavior of wrought and additive manufactured Ti-6Al-4V including surface finish effect, Int. J. Fatigue. 100, pp. 347-366.

DOI: $10.1016 /$ j.ijfatigue.2017.03.044.

[18] Thijs, L., Verhaeghe, F., Craeghs, T., Van Humbeeck, J., Kruth, J.P. (2010). A Study of the Microstructural Evolution During Selective Laser Melting of Ti-6Al-4V, Acta Mater. 58, pp. 3303-3312. DOI: 10.1016/j.actamat.2010.02.004.

[19] Wu, M., Itoh, T., Shimizu, Y., Nakamura, H., Takanashi, M. (2012). Low cycle fatigue life of Ti-6Al-4V alloy under non-proportional loading, Int. J. Fatigue. 44, pp. 14-20. DOI: 10.1016/j.ijfatigue.2012.06.006. 